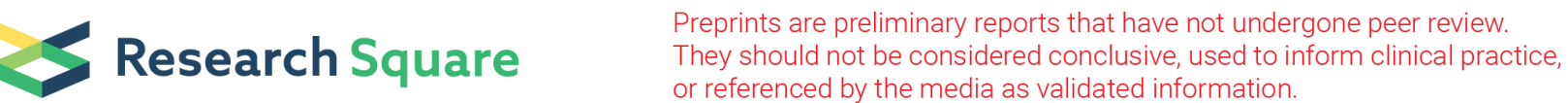

\section{Diabetes Distress, Medication Taking, Glycaemic Control and Self-Management: Comparing a Minority Migrant Group With Mainstream Society}

Hamzah Alzubaidi ( $\sim$ halzubaidi@sharjah.ac.ae)

University of Sharjah

Catarina Samorinha

University of Sharjah https://orcid.org/0000-0002-6662-0347

Hana Sulieman

American University of Sharjah

Kevin Mc Namara

Deakin University

Colette Browning

Federation University Australia

Research Article

Keywords: Diabetes, Distress, Adherence, Self-Management, Glycated Hemoglobin A

Posted Date: April 26th, 2021

DOI: https://doi.org/10.21203/rs.3.rs-405016/v1

License: (c) (1) This work is licensed under a Creative Commons Attribution 4.0 International License.

Read Full License 


\section{Abstract \\ Background}

Diabetes distress (DD) has broad-ranging effects on type 2 diabetes (T2DM) management and outcomes. DD research is scarce among ethnic minority groups, particularly Arabic-speaking immigrant communities. To improve outcomes for these vulnerable groups, healthcare providers, including pharmacists, need to understand modifiable predictors of DD.

\section{Objective}

To assess and compare DD and its association with medication-taking behaviours, glycaemic control, self-management, and psychosocial factors among first-generation Arabic-speaking immigrants and English-speaking patients of Anglo-Celtic background with diabetes, and determine DD predictors. Setting: Various healthcare settings in Australia. Method: A multicentre cross-sectional study was conducted. Adults with T2DM completed a survey comprised of validated tools. Glycated haemoglobin, blood pressure, and lipid profile were gathered from medical records. Multiple linear regression models were computed to assess the DD predictors. Main outcome measure: Diabetes distress level.

\section{Results}

Data was analysed for 696 participants: $56.3 \%$ Arabic-speaking immigrants and $43.7 \%$ English-speaking patients. Compared with English-speaking patients, Arabic-speaking immigrants had higher DD, lower medication adherence, worse self-management and glycaemic control, and poorer health and clinical profile. The regression analysis demonstrated that higher DD in Arabic-speaking immigrants was associated with cost-related medication underuse and lower adherence to exercise, younger age, lower education level, unemployment, lower self-efficacy, and inadequate glycaemic control. Whereas among English-speaking patients, higher DD was associated with both cost- and non-cost-related underuse of medication and lower dietary adherence.

\section{Conclusion}

Results provided new insights to guide healthcare providers on reducing the apparent excess burden of DD among Arabic-speaking immigrants and potentially improve medication adherence, glycaemic control, and self-management.

\section{Impacts On Practice}

- Our study revealed that compared with English-speaking patients, Arabic-speaking immigrants had higher DD, lower medication adherence, worse glycaemic control and self-management, and poorer 
health and clinical profile.

- Integrating DD assessment into medical assessments and pharmacists' practices is crucial, particularly for migrant groups, who typically have higher DD levels.

- Future interventions may achieve meaningful reductions in DD among Arabic-speaking immigrants if they improve medication adherence and focus on improving self-management and glycaemic control.

- At a policy level, our findings provide further evidence around health-system and societal issues such as healthcare affordability and societal acculturation that have a significant impact on DD, and which need to be addressed systematically to achieve equitable health outcomes for Arabic-speaking immigrants and other vulnerable migrant groups.

\section{Introduction}

Globally, diabetes is associated with significant morbidity and burden. Its prevalence continues to increase and is projected to reach $10.4 \%$ by 2040 , placing increasing demands on healthcare systems [1]. Urgent actions are needed to combat this global burden, including better support for patients to achieve optimal self-management $[2,3]$.

Successful integration of diabetes care into daily life is challenging. Most individuals are expected to comprehend large amounts of information about diabetes and its treatment, make many selfmanagement decisions, spend substantial time often performing complex self-care activities, and access multiple healthcare services $[4,5]$. Therefore, it is unsurprising that diabetes distress (DD) is prevalent among people with type 2 diabetes (T2DM) [6, 7]. The prevalence of moderate and severe DD among adults with T2DM varies globally; it has been reported to be as high as $45.4 \%$ in community settings [8]. DD is rooted in how patients experience diabetes management within their socio-cultural environment, and it refers to the emotional burdens, worries, and concerns among individuals living with this progressive, challenging disease [9]. Previous studies demonstrated significant linkages between DD and poor glycaemic control, worse self-management activities, low quality of life and self-efficacy, and increased morbidity levels and healthcare costs [9-15].

Multidisciplinary integrated team-based approach, structured patient-centred support, and appropriate follow-up mechanisms have led to improvements in diabetes control $[16,17]$. Pharmacist-led diabetes management program improved the care and outcomes of people with diabetes including ethnic minorities $[18,19]$. Despite being important for the comprehensive management of T2DM, healthcare providers including pharmacists often fail to screen for or assess DD. Delaying early detection of DD negatively impacts patients' quality of life and increases healthcare costs [14]. Psycho-education interventions designed to reduce DD have demonstrated improved health outcomes, particularly among those who are not achieving clinical goals or have difficulty adhering to their prescribed treatment and lifestyle modifications [20, 21]. 
In recent years, the increasing ethnic diversity among patients with diabetes in upper-middle and highincome western countries has received growing attention. DD levels are higher among migrant communities compared with the general population [22]. These minority groups often have poorer health outcomes, higher morbidity rates, lower health literacy, face more barriers to access and use of healthcare services, and often receive less medical information from their doctors compared with mainstream society $[23,24]$.

There is a paucity of data about DD and contributing factors among Arabic-speaking immigrant communities in western countries [22]. Our previous research among this rapidly growing minority identified that they have poorer glycaemic control, reduced adherence to self-management activities and prescribed medications, experience more challenges in accessing health services, and negative health beliefs when compared with English-speaking people of Anglo-Celtic origin [25-27]. To date, no previous study assessed all these factors that are postulated to be associated with DD among Arabic-speaking immigrant communities.

\section{Aim Of The Study}

The study aimed to assess and compare DD level and understand its relationship with key clinical, behavioural, psychosocial, and sociodemographic factors among Arabic-speaking immigrants and English-speaking patients of Anglo-Celtic background with T2DM (comparison group) and determine the extent to which these factors predict DD levels. Such assessment would be used to guide clinicians and pharmacists to improve medication adherence, glycaemic control and self-management among Arabicspeaking immigrant communities.

\section{Method}

\section{Ethics approval}

Ethics approval was obtained from the Monash University Human Research Ethics Committee (CF09/0956: 2009000462) and ethics committees at participating hospitals.

\section{Study design and setting}

A multicentre cross-sectional study was conducted in various healthcare settings in metropolitan and rural Victoria, Australia. Participants were recruited through diabetes outpatient clinics at three major hospitals, ten primary care practices, and five community support groups. Rural participants were recruited through diabetes outpatient clinics at a major rural hospital and its associated clinics, three general medical practices, and various community support groups in Shepparton.

\section{Study participants}


People attending participating clinics were invited to complete study questionnaire while waiting for their appointments. Those who expressed interest were screened for eligibility via a brief researcheradministered checklist. Inclusion criteria were a diagnosis of T2DM and aged $\geq 18$ years. Participants were recruited into two groups based on self-reported ethnic background. First, Arabic-speaking firstgeneration immigrants whose first language was Arabic and born in any of the 22 countries of the Arab League were selected. Second, Australian English-speaking participants of Anglo-Celtic identity and born in North America, Australia, United Kingdom, Ireland, or New Zealand were selected. Eligible consenting patients completed a paper-based questionnaire immediately after consenting. On average, participants took 45 minutes to complete the survey.

\section{Development of the questionnaire}

After a thorough literature review, it was postulated that DD is associated with four main factors: sociodemographic, behavioural (medication-taking behaviours and self-management), clinical (glycated haemoglobin and health status), and psychosocial (functional health literacy and self-efficacy) [9-15]. This conceptual framework (Fig. 1) informed questionnaire development.

The first section of the questionnaire measured sociodemographic and health characteristics. The second section assessed psychosocial and behavioural factors using validated and reliable tools and items, including:

\section{Medication-taking behaviours}

Medication adherence was measured using the modified Morisky scale [28]. This scale consists of four items, scored as 'Yes' (0) or 'No' (1). Based on the total score, patients were categorised as either adherent (total score $=4$ ) or non-adherent (total score < 4). Participants' medication underuse in the past 12 months was measured by two items used in previous studies [29], and data was presented in four categories: no underuse, cost-related underuse, non-cost related underuse, and both cost- and non-cost-related underuse.

\section{Diabetes self-management}

The Summary of Diabetes Self-Care Activities (SDSCA) was used to assess adherence to dietary behaviours, exercise, blood glucose testing, foot care, and smoking status [30]. The SDSCA is a brief, reliable, and valid measure that is widely used globally and it has 11 items measuring the number of days in the previous week that patients have engaged in self-care activities on a scale of 0-7 [30]. Data is reported as the mean days of activity in the prior week.

\section{Health literacy and self-efficacy}

Functional health literacy was assessed using three validated items measuring difficulties in reading medical forms or learning about medical conditions [31]. This instrument provides a total score that can be dichotomized into adequate functional health literacy (scores $\geq 10$ ) and inadequate functional health literacy (scores $<10$ ). Self-efficacy was defined as the confidence a participant feels about conducting two specific tasks: taking diabetes medicines as prescribed and performing self-care activities 
successfully. Participants recorded their response on a 5-point Likert scale, categorized as not confident (responses 1-3) or confident (responses 4-5). These two items have been validated among patients with diabetes [32, 33].

\section{Diabetes distress (main outcome measure)}

Diabetes distress level was assessed using the Diabetes Distress Scale (DDS-17) [34]. This brief validated and reliable scale has 17 items in four subscales: emotional burden, physician-related distress, regimenrelated distress, and interpersonal distress. Participants' responses were recorded on a scale of 0 to 5 ; they were asked to indicate the degree to which each 'issue' might have distressed them in their daily lives. A total score (range: 0-85) was calculated for each patient; higher scores represent higher DD levels.

The last section collected the most recently documented clinical tests within the last 12 months of HbA1c level, blood pressure and lipid panel. Data was retrieved from medical records with participant consent. The questionnaire was pilot-tested among three academics, two diabetes educators, and nine patients for clarity and the time to complete the questionnaire and to establish face and content validities. It was translated into Arabic by a professional translation service. The Arabic version was back-translated into English. The two versions were compared, and no differences were detected.

\section{Sample size}

If significant difference in the mean DD levels exists between the Arabic-speaking immigrants and mainstream, the obtained sample size of 701 enabled us to determine the significance of a mean absolute minimum difference of 2.7 (standard deviation 10.0) in DD scores between Arabic-speaking immigrants the mainstream group with a test power of $95 \%$. Only participants with data on the outcome variable, which is DD, were included in the analysis.

\section{Data analysis}

Data were analysed using both SPSS Statistics for Windows, version 27.0, Armonk, NY, USA, and Minitab version 17.3. Data are summarized in percentages for categorical variables, mean \pm standard deviation (SD) for continuous variables, and mean differences [95\% confidence interval (CI)] for comparing two continuous variables. Bivariate associations between the two ethnic groups and other categorical variables were analysed using the Pearson Chi-square test, and the results were reported as numbers and percentages. Bivariate associations between continuous normally distributed variables were tested with Pearson's Correlation ( $r$ ). Mean differences in the DD levels were tested through Independent-samples TTest or one-way ANOVA, when the variables had more than two categories. All tests are two-tailed, and $P$ values $<0.05$ are considered statistically significant.

Multiple linear regression was used to model the extent to which the covariates in question could predict DD levels. Significant covariates for predicting diabetes distress were declared at a $5 \%$ significance level. All analyses were stratified by the two groups. 


\section{Results}

\section{Study participants}

Data was analysed for 696 participants, data for five further participants were removed as they did not complete the DD section: 392 were first-generation Arabic-speaking immigrants and 304 English-speaking participants. Sociodemographic, clinical, behavioural and psychosocial characteristics are summarized in Table 1. Arabic-speaking immigrants were significantly younger than the English-speaking $(p=0.001)$, more frequently had an education level below high school $(p=0.005)$, had an inadequate functional health literacy $(p<0.001)$, and a shorter duration of diabetes $(p<0.001)$ than the English-speaking. Significantly more Arabic-speaking immigrants were non-adherent to their prescribed medication compared with English-speaking patients $(p<0.001)$ and they also reported more cost-related and non-cost-related medication underuse $(p<0.001)$. Comparing to English-speaking group, Arabic-speaking immigrants had a higher use of oral hypoglycaemic agents (OHAs) $(p<0.001)$ and insulin $(p<0.001)$. Documentation of clinical parameters was incomplete for a considerably higher proportion of Arabic-speaking immigrants. Among those with documented clinical values, Arabic-speaking immigrants more frequently had an inadequate glycaemic control [HbA1c $>7 \%(>53 \mathrm{mmol} / \mathrm{mol})](p=0.047)$, high blood pressure $(p=0.020)$ and elevated levels of total cholesterol $(p<0.001)$ and HDL $(p=0.001)$ compared to English-speaking patients.

\section{Diabetes distress levels}

As shown in Figure 2, Arabic-speaking immigrants had significantly higher total DD levels $(p<0.001)$ than English-speaking patients. This trend was also observed in three domains: emotional burden, regimenrelated distress, and diabetes-related interpersonal distress ( $p<0.001 \mathrm{for}$ all).

\section{Diabetes distress and sociodemographic characteristics, by ethnicity}

A negative weak correlation was found between DD levels and age in both Arabic-speaking $(p=0.009)$ and English-speaking patients $(p<0.001)$, meaning that older patients had lower levels of DD (Table 2). Among Arabic-speaking immigrants, higher DD levels were reported among those with lower levels of education $(p=0.004)$, those with inadequate functional health literacy $(p<0.001)$, and patients who were not employed $(p<0.001)$.

\section{Diabetes distress and clinical characteristics, by ethnicity}

Mean DD level was significantly different according to perceived health status among Arabic-speaking and English-speaking patients: those with poor health status presented higher DD levels $(p<0.001$ and $p=0.002$, respectively). Among Arabic-speaking immigrants, those with a longer duration of diabetes had significantly lower distress levels $(p=0.007)$. Those with co-morbidities and with inadequate glycaemic control $[\mathrm{HbA} 1 \mathrm{c}>7 \%$ ( $>53 \mathrm{mmol} / \mathrm{mol})]$ had higher levels of DD ( $p=0.003$ and $p<0.001$, respectively). Among English-speaking patients, weak positive correlations were found between DD levels and HDL levels $(p=0.007)$. 


\section{Diabetes distress and behavioural and psychosocial characteristics, by ethnicity}

For both groups, greater adherence to dietary recommendations was weakly correlated with lower levels of $\mathrm{DD}$ ( $p<0.001$ in both groups). In the Arabic-speaking group, exercise, self-monitoring of blood glucose, and foot care were moderately negatively correlated with $\mathrm{DD}$ ( $p<0.001$ for all the correlations). Also in this group, higher levels of DD were found among those who are non-adherent to medication $(p<0.001)$.

Those reporting cost-related medication underuse had significantly higher mean DD levels for both Arabic-speaking immigrants and English-speaking patients than those reporting no underuse $(p=0.017$ and $p<0.001$, respectively). Also, among English-speaking, those reporting both cost- and non-cost-related underuse had significantly higher DD levels compared with participants who reported non-cost-related underuse only $(p<0.001)$.

In both groups, there were significant differences in DD levels according to self-efficacy. DD level was lower among participants who were confident about taking diabetes medication precisely as prescribed ( $p<0.001$ among Arabic-speaking and $p=0.015$ among English-speaking) and who were confident in their ability to carry out self-care activities ( $p<0.001$ among Arabic-speaking and $p=0.001$ among Englishspeaking).

\section{Prediction of diabetes distress}

The total DD score of both groups was regressed onto all significant covariates (Table 3). Overall, our regression models were able to explain $52 \%$ of the variation in DD scores for Arabic-speaking immigrants and 35\% for English-speaking participants.

In the Arabic-speaking group, younger patients $(p<0.001)$, those with lower education levels (less than high school) compared to those with a high school level $(p=0.026)$, and those who were not employed $(p=0.009)$ were more likely to present higher DD levels. Moreover, higher levels of DD among Arabicspeaking patients were predicted by inadequate glycaemic control [HbA1c $>7 \%(>53 \mathrm{mmol} / \mathrm{mol})]$ $(p=0.006)$, poor health status $(p=0.028)$, lower adherence to exercise $(p=0.006)$, cost-related underuse of medication $(p<0.001)$, and lack of confidence in carrying out self-care activities $(p=0.009)$.

In the English-speaking group, being younger $(p<0.001)$, having lower adherence to dietary behaviour recommendations $(p=0.004)$ and reporting both cost- and non-cost-related underuse of medication $(p=0.002)$ predicted higher levels of DD.

\section{Discussion}

This study is the first to assess DD and its correlation with medication-taking behaviours, glycaemic control, self-management practices, and self-efficacy among Arabic-speaking immigrants and Englishspeaking patients with T2DM in an upper-income western country. Similar to the recent findings from the Dutch Diabetes Pearl Cohort, our Arabic-speaking immigrants had higher DD levels, lower medication adherence, and worse self-management practices and health outcomes compared with Caucasian 
participants [35]. Consistent with previous research with diabetic patients [10], a strong correlation between $\mathrm{DD}$ and $\mathrm{HbA1c}$ was found in our study, but only among Arabic-speaking immigrants.

Pharmacists have contributed significantly to improve diabetes management [36, 37]. There are several modalities for pharmacist's involvement in diabetes care, including disease management, education, medication counseling, screening for CVD risk factors, referral, and follow-up [18, 38, 39]. However, the active screening for DD has not yet been integrated into existing pharmacist-led diabetes interventions. Our results demonstrated a significant association between medication adherence and underuse and DD levels. This calls for pharmacists to focus their future efforts on integrating DD assessment into their encounters with patients with T2DM, especially those from ethnic minority groups who typically have higher DD levels. Pharmacists could use brief and simple self-report measures to assess DD levels, facilitating such assessment into routine care [40].

In multivariate analysis, age was strongly associated with DD in both groups after controlling for the effect of other factors. The overall ability of the regression model to explain $52 \%$ of the variation in DD among Arabic-speaking immigrants was impressive, compared with just 35\% for English-speaking patients. Self-efficacy was a substantial contributor to DD among both groups. The apparent excess burden of DD among Arabic-speaking immigrants may indicate less appropriate healthcare models, access inequalities, and/or greater challenges with self-management [41].

Consistent with previous studies, our results demonstrated that younger age was associated with higher DD levels in both groups [13,42]. Successful diabetes management requires patients to engage and maintain complex self-management behaviours. Within this context, it is postulated that those older individuals who typically have longer diabetes duration have a better opportunity to adopt and improve these self-management activities and integrate them into a daily routine. Moreover, compared to younger individuals, older adults are expected to have more time to accept disease diagnosis and build resilience and emotion regulation strategies to respond to diabetes demands [43]. Among Arabic-speaking patients, a cost-related underuse of medication, a lower educational level, and being unemployed predicted higher DD levels. This constellation of factors is revealing of how health is influenced by interactions between environment, social and economic factors [44], which are unequally distributed, often penalizing individuals belonging to ethnical minorities.

It has been demonstrated that DD levels can be reduced with appropriate intervention [8]. Previous strategies to reduce DD relied on educational, behavioural/skill-based interventions (aiming at improving diabetes self-management knowledge, problem solving, goal setting, action planning) while the psychological intervention focused on the remediation of diabetes worries that underlie DD [8, 21, 45]. Our results suggest that DD-inclusive interventions might have a particularly large impact on T2DM outcomes for Arabic-speaking migrant especially for those with high initial DD levels, and the focus of such intervention should be on promoting adherence to medication and self-management activities, and improving self-efficacy. 


\section{Strengths and weaknesses}

Some limitations must be acknowledged. The cross-sectional design precluded cause-effect inferences of the observed correlations. The negative relationship between DD levels and self-management can be interpreted in two directions: increased DD can negatively impact self-management behaviours [46], and also the difficulty in performing self-management could contribute to develop or increase DD [10]. Thus, to avoid reverse causality, future studies must include DD and self-management in longitudinal analyses to establish the direction and causality. Caution must be exercised in generalizing study findings to all Arabic-speaking immigrants due to the non-random sampling and heterogeneity of this group. However, this was mitigated by recruiting a large and diverse sample from various primary, secondary, and tertiary healthcare settings in metropolitan and rural areas. The comprehensive assessment of factors known to be associated with DD and the inclusion of these in the regression model to identify modifiable predictors to be used as starting point to develop targeted interventions is another major strength.

\section{Conclusion}

Arabic-speaking immigrants had higher DD levels, lower medication adherence and worse selfmanagement compared with English-speaking patients. Healthcare providers must routinely screen for and assess DD as part of comprehensive diabetes care, particularly among Arabic-speaking immigrants. The identified modifiable factors that predicted higher DD levels among Arabic-speaking immigrants were low adherence rates to medication and exercise, and low-self-efficacy.

\section{Declarations}

Funding: This research was supported by an operational grant from the University of Sharjah and an internal grant from the Centre for Medicine Use and Safety, Monash University.

Conflicts of interest: The authors declare that they have no conflicts of interest.

Author contributions: HA designed the study, collected and partially analysed data, wrote, reviewed and edited the manuscript. HS conducted bivariate and multivariate analysis and edited the manuscript. KM contributed significantly to the discussion, reviewed and edited the manuscript. CB reviewed and edited the manuscript. CS contributed significantly to data analysis and interpretation, created tables, and edited the manuscript.

Availability of data and material (data transparency): Data is available from the author by request.

Code availability (software application or custom code): Not applicable.

Additional declarations for articles in life science journals that report the results of studies involving humans and/or animals: Not applicable. 
Ethics approval: Approval was obtained from the Monash University Human Research Ethics Committee (CF09/0956: 2009000462) and ethics committees at participating hospitals.

Acknowledgments: The authors sincerely thank study participants for sharing their real views and experiences, and staff who supported recruitment at the participating study sites. Special thanks to Mr. Ward Saidawi for his outstanding efforts in data management.

\section{References}

1. Ogurtsova K, da Rocha Fernandes JD, Huang Y, Linnenkamp U, Guariguata L, Cho NH, et al. IDF Diabetes Atlas: Global estimates for the prevalence of diabetes for 2015 and 2040. Diabetes Research and Clinical Practice. 2017;128:40-50.

2. Bommer C, Heesemann E, Sagalova V, Manne-Goehler J, Atun R, Bärnighausen T, et al. The global economic burden of diabetes in adults aged 20-79 years: a cost-of-illness study. The Lancet Diabetes \& Endocrinology. 2017;5(6):423-30.

3. Stark SC, Fradkin JE, Saydah SH, Rust KF, Cowie CC. The Prevalence of Meeting A1C, Blood Pressure, and LDL Goals Among People With Diabetes, 1988-2010. Diabetes Care. 2013;36(8):2271-9.

4. Young-Hyman D, de Groot M, Hill-Briggs F, Gonzalez JS, Hood K, Peyrot M. Psychosocial Care for People With Diabetes: A Position Statement of the American Diabetes Association. Diabetes Care. 2016;39(12):2126-40.

5. Guo H, Wang X, Mao T, Li X, Wu M, Chen J. How psychosocial outcomes impact on the self-reported health status in type 2 diabetes patients: Findings from the Diabetes Attitudes, Wishes and Needs (DAWN) study in eastern China. PLoS One. 2018;13(1):e0190484.

6. Fisher L, Skaff MM, Mullan JT, Arean P, Mohr D, Masharani U, et al. Clinical Depression Versus Distress Among Patients With Type 2 Diabetes. Diabetes Care. 2007;30(3):542-8.

7. Das-Munshi J, Stewart R, Ismail K, Bebbington PE, Jenkins R, Prince MJ. Diabetes, common mental disorders, and disability: findings from the UK National Psychiatric Morbidity Survey. Psychosom Med. 2007;69(6):543-50.

8. Fisher L, Hessler D, Glasgow RE, Arean PA, Masharani U, Naranjo D, et al. REDEEM: A Pragmatic Trial to Reduce Diabetes Distress. Diabetes Care. 2013;36:2551-8.

9. Fisher L, Hessler DM, Polonsky WH, Mullan J. When Is Diabetes Distress Clinically Meaningful?: Establishing cut points for the Diabetes Distress Scale. Diabetes Care. 2012;35(2):259-64.

10. Fisher L, Mullan JT, Arean P, Glasgow RE, Hessler D, Masharani U. Diabetes Distress but Not Clinical Depression or Depressive Symptoms Is Associated With Glycemic Control in Both Cross-Sectional and Longitudinal Analyses. Diabetes Care. 2010;33(1):23-8.

11. Chew B-H, Mohd-Sidik S, Shariff-Ghazali S. Negative effects of diabetes-related distress on healthrelated quality of life: an evaluation among the adult patients with type 2 diabetes mellitus in three primary healthcare clinics in Malaysia. Health and Quality of Life Outcomes. 2015;13:187. 
12. van Dooren FEP, Nefs G, Schram MT, Verhey FRJ, Denollet J, Pouwer F. Depression and Risk of Mortality in People with Diabetes Mellitus: A Systematic Review and Meta-Analysis. PLOS ONE. 2013;8(3):e57058.

13. Fisher L, Mullan JT, Skaff MM, Glasgow RE, Arean P, Hessler D. Predicting diabetes distress in patients with Type 2 diabetes: a longitudinal study. Diabet Med. 2009;26(6):622-7.

14. Polonsky WH, Anderson B, Lohrer P, Welch G, Jacobson A, Aponte J, et al. Assessment of diabetesrelated distress. Diabetes Care. 1995;18(6):754 - 60.

15. Jannoo Z, Wah YB, Lazim AM, Hassali MA. Examining diabetes distress, medication adherence, diabetes self-care activities, diabetes-specific quality of life and health-related quality of life among type 2 diabetes mellitus patients. Journal of Clinical \& Translational Endocrinology. 2017;9:48-54.

16. Rose Maljanian, Neil Grey, Ilene Staff, Cruz-Marino-Aponte M. Improved Diabetes Control Through a Provider-Based Disease Management Program. Disease Management and Health Outcomes volume. 2002;10:1-8.

17. Chris Miller-Rosales, Rodriguez HP. Interdisciplinary Primary Care Team Expertise and Diabetes Care Management. The Journal of the American Board of Family Medicine. 2021;34(1):151-61.

18. Campbell RK. Role of the pharmacist in diabetes management. American journal of health-system pharmacy : AJHP : official journal of the American Society of Health-System Pharmacists. 2002;59 Suppl 9:S18-21.

19. Rashid JR, Leath BA, Truman BI, Atkinson DD, Gary LC, Manian N. Translating Comparative Effectiveness Research Into Practice: Effects of Interventions on Lifestyle, Medication Adherence, and Self-care for Type 2 Diabetes, Hypertension, and Obesity Among Black, Hispanic, and Asian Residents of Chicago and Houston, 2010 to 2013. Journal of public health management and practice : JPHMP. 2017;23(5):468-76.

20. Dieter T, Lauerer J. Depression or Diabetes Distress? Perspectives in Psychiatric Care. 2018;54(1):847.

21. Sturt J, Dennick K, Hessler D, Hunter BM, Oliver J, Fisher L. Effective interventions for reducing diabetes distress: systematic review and meta-analysis. International Diabetes Nursing. 2015(12):4055.

22. Schmidt CB, Potter van Loon BJ, Torensma B, Snoek FJ, Honig A. Ethnic Minorities with Diabetes Differ in Depressive and Anxiety Symptoms and Diabetes-Distress. Journal of Diabetes Research. 2017;2017:1204237.

23. Attridge M, Creamer J, Ramsden M, Cannings-John R, Hawthorne K. Culturally appropriate health education for people in ethnic minority groups with type 2 diabetes mellitus. Cochrane Database of Systematic Reviews. 2014(9):CD006424.

24. Tenkorang EY. Early onset of type 2 diabetes among visible minority and immigrant populations in Canada. Ethnicity \& Health. 2017;22:266-84.

25. Alzubaidi H, Mc Narmara K, Kilmartin G, Kilmartin J, Marriott J. The relationships between illness and treatment perceptions with adherence to diabetes self-care: A comparison between Arabic-speaking 
migrants and Caucasian English-speaking patients. Diabetes Research and Clinical Practice. 2015;110(2):208-17.

26. Alzubaidi H, Mc Namara K, Browning C, Marriott J. Barriers and enablers to healthcare access and use among Arabic-speaking and Caucasian English-speaking patients with type 2 diabetes mellitus: a qualitative comparative study. BMJ Open. 2015;5(11).

27. Alzubaidi H, Mc Mamara K, Chapman C, Stevenson V, Marriott J. Medicine-taking experiences and associated factors: comparison between Arabic-speaking and Caucasian English-speaking patients with Type 2 diabetes. Diabetic Medicine. 2015:n/a-n/a.

28. Morisky DE, Green LW, Levine DM. Concurrent and Predictive Validity of a Self-Reported Measure of Medication Adherence. Medical Care. 1986;24(1):67-74.

29. Aikens JE, Piette JD. Diabetic Patients' Medication Underuse, Illness Outcomes, and Beliefs About Antihyperglycemic and Antihypertensive Treatments. Diabetes Care. 2009;32(1):19-24.

30. Toobert D, Hampson S, Glasgow R. The summary of diabetes self-care activities measure: results from 7 studies and a revised scale. Diabetes Care. 2000;23:943 - 50.

31. Peterson PN, Shetterly SM, Clarke CL, Bekelman DB, Chan P, Allen LA, et al. Health literacy and outcomes among patients with heart failure. JAMA: The Journal of the American Medical Association. 2011;305(16):1695-701.

32. Chao J, Nau DP, Aikens JE, Taylor SD. The mediating role of health beliefs in the relationship between depressive symptoms and medication adherence in persons with diabetes. Research in Social and Administrative Pharmacy. 2005;1(4):508-25.

33. Cherrington A, Wallston K, Rothman R. Exploring the relationship between diabetes self-efficacy, depressive symptoms, and glycemic control among men and women with type 2 diabetes. Journal of Behavioral Medicine. 2010;33(1):81-9.

34. Polonsky WH, Fisher L, Earles J, Dudl RJ, Lees J, Mullan J, et al. Assessing Psychosocial Distress in Diabetes. Diabetes Care. 2005;28(3):626-31.

35. Özcan B, Rutters F, Snoek FJ, Roosendaal M, Sijbrands EJ, Elders PJM, et al. High Diabetes Distress Among Ethnic Minorities Is Not Explained by Metabolic, Cardiovascular, or Lifestyle Factors: Findings From the Dutch Diabetes Pearl Cohort. Diabetes Care. 2018;41(9):1854-61.

36. Pousinho S, Morgado M, Falcão A, Alves G. Pharmacist Interventions in the Management of Type 2 Diabetes Mellitus: A Systematic Review of Randomized Controlled Trials. Journal of managed care \& specialty pharmacy. 2016;22(5):493-515.

37. Armor BL, Britton ML, Dennis VC, Letassy NA. A review of pharmacist contributions to diabetes care in the United States. Journal of pharmacy practice. 2010;23(3):250-64.

38. Pousinho S, Morgado M, Plácido Al, Roque F, Falcão A, Alves G. Clinical pharmacists' interventions in the management of type 2 diabetes mellitus: a systematic review. Pharmacy practice. 2020;18(3):2000.

39. Alsuwayni B, Alhossan A. Impact of clinical pharmacist-led diabetes management clinic on health outcomes at an academic hospital in Riyadh, Saudi Arabia: A prospective cohort study. Saudi 
pharmaceutical journal : SPJ : the official publication of the Saudi Pharmaceutical Society. 2020;28(12):1756-9.

40. Dennick K, Sturt J, Speight J. What is diabetes distress and how can we measure it? A narrative review and conceptual model. Journal of Diabetes and Its Complications. 2017;31:898-911.

41. Abuelezam NN, Abdulrahman ME-S, Galea S. The Health of Arab Americans in the United States: An Updated Comprehensive Literature Review. Frontiers in Public Health. 2018;6:1-18.

42. Nguyen V, Tran T, Dang T, Nguyen V, Tran B, Le CV, et al. Diabetes-Related Distress and Its Associated Factors Among Patients with Diabetes in Vietnam. Psychol Res Behav Manag. 2020;13:1181-9.

43. Helgeson VS, Van Vleet M, Zajdel M. Diabetes stress and health: Is aging a strength or a vulnerability? J Behav Med. 2020;43:426-36.

44. Dahlgren G, Whitehead M. Policies and Strategies to Promote Social Equity in Health. Stockholm, Sweden Institute for Futures Studies; 1991.

45. Mathiesen AS, Egerod I, Jensen T, Kaldan G, Langberg H, Thomsen T. Psychosocial interventions for reducing diabetes distress in vulnerable people with type 2 diabetes mellitus: a systematic review and meta-analysis. Diabetes Metab Syndr Obes. 2018;12:19-33.

46. Hoogendoorn CJ, Schechter CB, Llabre MM, Walker EA, Gonzalez JS. Distress and Type 2 Diabetes Self-Care: Putting the Pieces Together. Annals of Behavioral Medicine. 2020;epub ahead of print.

\section{Tables}


Table 1. Description and comparison of participants' sociodemographic, clinical, behavioural and psychosocial characteristics, by ethnicity $(\mathrm{N}=696)$

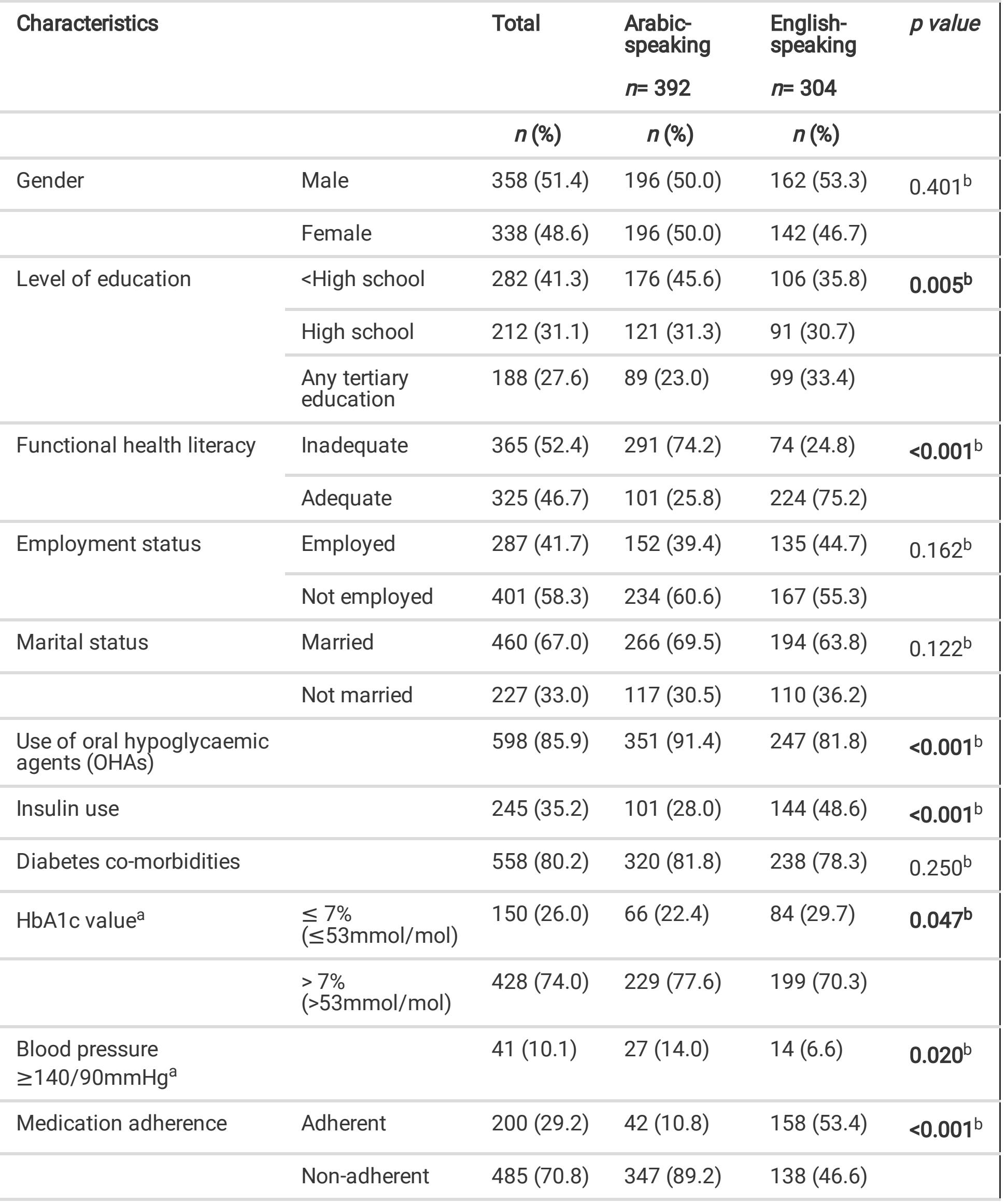




\begin{tabular}{|c|c|c|c|c|c|}
\hline Medication underuse & No underuse & 315 (45.7) & $100(25.5)$ & $215(72.4)$ & $<0.001^{b}$ \\
\hline & Cost-related & $112(16.3)$ & $100(25.5)$ & $12(4.0)$ & \\
\hline & Non-cost-related & $216(31.3)$ & $156(39.8)$ & $60(20.2)$ & \\
\hline & $\begin{array}{l}\text { Both cost- and } \\
\text { non-cost }\end{array}$ & $46(6.7)$ & $36(9.2)$ & $10(3.4)$ & \\
\hline & & $\begin{array}{l}\text { mean } \\
(S D)\end{array}$ & $\begin{array}{l}\text { mean } \\
(S D)\end{array}$ & $\begin{array}{l}\text { mean } \\
(S D)\end{array}$ & \\
\hline Age (years) & & $59.1(8.9)$ & $58.1(8.0)$ & $60.4(9.7)$ & $0.001^{c}$ \\
\hline Diabetes duration (years) & & $8.7(6.8)$ & $7.2(4.6)$ & $10.5(8.4)$ & $<0.001^{c}$ \\
\hline Total cholesterol $^{\mathrm{a}}$ & & $4.6(1.6)$ & $5.0(1.8)$ & $4.3(1.2)$ & $<0.001^{c}$ \\
\hline $\operatorname{LDL}^{\mathrm{a}}$ & & $2.3(0.8)$ & $2.4(0.7)$ & $2.3(0.9)$ & $0.144^{c}$ \\
\hline $\mathrm{HDL}^{\mathrm{a}}$ & & $1.4(0.8)$ & $1.5(0.9)$ & $1.2(0.6)$ & $0.001^{c}$ \\
\hline
\end{tabular}


Table 2. Mean differences of diabetes distress level according to participants' sociodemographic, clinical, behavioural and psychosocial characteristics, stratified by ethnicity

Diabetes distress level

\begin{tabular}{|c|c|c|}
\hline $\begin{array}{l}\text { Arabic- } \\
\text { speaking }\end{array}$ & $p$ value & $\begin{array}{l}\text { English- } \\
\text { speaking }\end{array}$ \\
\hline $\begin{array}{l}\text { mean } \\
(S D)\end{array}$ & & $\underset{(S D)}{\text { mean }}$ \\
\hline
\end{tabular}

Sociodemographic characteristics

\begin{tabular}{|c|c|c|c|c|c|}
\hline \multirow[t]{2}{*}{ Gender } & Male & $\begin{array}{l}27.78 \\
(9.41)\end{array}$ & $0.157^{b}$ & $\begin{array}{l}20.61 \\
(16.32)\end{array}$ & $0.814^{\mathrm{b}}$ \\
\hline & Female & $\begin{array}{l}29.37 \\
(12.42)\end{array}$ & & $\begin{array}{l}20.18 \\
(15.30)\end{array}$ & \\
\hline \multicolumn{2}{|l|}{ Age (years), correlation } & -0.133 & $0.009^{c}$ & -0.271 & $<0.001^{\circ}$ \\
\hline \multirow[t]{3}{*}{ Level of education } & $<$ High school & $\begin{array}{l}30.44 \\
(12.05)^{\mathrm{e}}\end{array}$ & $0.004^{d}$ & $\begin{array}{l}18.47 \\
(15.41)\end{array}$ & $0.063^{d}$ \\
\hline & High school & $\begin{array}{l}27.87 \\
(9.78)\end{array}$ & & $\begin{array}{l}23.40 \\
(17.50)\end{array}$ & \\
\hline & $\begin{array}{l}\text { Any tertiary } \\
\text { education }\end{array}$ & $\begin{array}{l}25.81 \\
(10.58)^{\mathrm{e}}\end{array}$ & & $\begin{array}{l}18.67 \\
(12.74)\end{array}$ & \\
\hline \multirow[t]{2}{*}{ Functional health literacy } & Inadequate & $\begin{array}{l}30.43 \\
(10.56)\end{array}$ & $<0.001^{b}$ & $\begin{array}{l}20.34 \\
(15.31)\end{array}$ & $0.800^{b}$ \\
\hline & Adequate & $\begin{array}{l}23.22 \\
(10.89)\end{array}$ & & $\begin{array}{l}20.88 \\
(15.98)\end{array}$ & \\
\hline \multirow[t]{2}{*}{ Employment status } & Employed & $\begin{array}{l}24.84 \\
(8.24)\end{array}$ & $<0.001^{b}$ & $\begin{array}{l}20.63 \\
(14.73)\end{array}$ & $0.842^{b}$ \\
\hline & Not employed & $\begin{array}{l}31.09 \\
(12.09)\end{array}$ & & $\begin{array}{l}20.26 \\
(16.78)\end{array}$ & \\
\hline \multirow[t]{2}{*}{ Marital status } & Married & $\begin{array}{l}28.92 \\
(11.84)\end{array}$ & $0.468^{b}$ & $\begin{array}{l}20.22 \\
(15.18)\end{array}$ & $0.782^{b}$ \\
\hline & Not married & $\begin{array}{l}28.03 \\
(9.40)\end{array}$ & & $\begin{array}{l}20.75 \\
(16.97)\end{array}$ & \\
\hline \multicolumn{6}{|l|}{ Clinical characteristics } \\
\hline \multicolumn{2}{|c|}{ Diabetes duration (years), correlation } & -0.142 & $0.007^{c}$ & 0.076 & $0.198^{c}$ \\
\hline $\begin{array}{l}\text { Use of oral hypoglycaemic } \\
\text { agents (OHAs) }\end{array}$ & Yes & $\begin{array}{l}28.57 \\
(10.78)\end{array}$ & $0.973^{b}$ & $\begin{array}{l}21.12 \\
(15.87)\end{array}$ & $0.145^{b}$ \\
\hline
\end{tabular}




\begin{tabular}{|c|c|c|c|c|c|}
\hline & No & $\begin{array}{l}28.63 \\
(14.38)\end{array}$ & & $\begin{array}{l}17.67 \\
(15.47)\end{array}$ & \\
\hline \multirow[t]{2}{*}{ Insulin use } & Yes & $\begin{array}{l}27.67 \\
(13.15)\end{array}$ & $0.413^{b}$ & $\begin{array}{l}21.07 \\
(15.36)\end{array}$ & $0.609^{b}$ \\
\hline & No & $\begin{array}{l}28.77 \\
(10.72)\end{array}$ & & $\begin{array}{l}20.13 \\
(16.55)\end{array}$ & \\
\hline \multirow[t]{2}{*}{ Diabetes co-morbidities } & Yes & $\begin{array}{l}29.38 \\
(10.40)\end{array}$ & $0.003^{b}$ & $\begin{array}{l}21.20 \\
(16.76)\end{array}$ & $0.100^{b}$ \\
\hline & No & $\begin{array}{l}25.03 \\
(13.34)\end{array}$ & & $\begin{array}{l}17.58 \\
(11.52)\end{array}$ & \\
\hline \multirow[t]{2}{*}{ HbA1c value ${ }^{a}$} & $\begin{array}{l}\leq 7 \% \\
(\leq 53 \mathrm{mmol} / \mathrm{mol})\end{array}$ & $\begin{array}{l}21.52 \\
(9.01)\end{array}$ & $<0.001^{b}$ & $\begin{array}{l}19.58 \\
(16.10)\end{array}$ & $0.572^{b}$ \\
\hline & $\begin{array}{l}>7 \% \\
(>53 \mathrm{mmol} / \mathrm{mol})\end{array}$ & $\begin{array}{l}28.86 \\
(12.13)\end{array}$ & & $\begin{array}{l}20.72 \\
(15.21)\end{array}$ & \\
\hline \multirow[t]{2}{*}{ Blood pressure $\geq 140 / 90 \mathrm{mmHg}^{\mathrm{a}}$} & Yes & $\begin{array}{l}29.11 \\
(9.48)\end{array}$ & $0.519^{b}$ & $\begin{array}{l}29.07 \\
(20.01)\end{array}$ & $0.099^{b}$ \\
\hline & No & $\begin{array}{l}27.73 \\
(10.37)\end{array}$ & & $\begin{array}{l}21.10 \\
(17.24)\end{array}$ & \\
\hline \multicolumn{2}{|l|}{ Total cholesterola ${ }^{\mathrm{a}}$, correlation } & 0.019 & $0.790^{c}$ & -0.026 & $0.720^{c}$ \\
\hline \multicolumn{2}{|l|}{ LDL $^{\mathrm{a}}$, correlation } & 0.025 & $0.727^{c}$ & -0.003 & $0.967^{c}$ \\
\hline \multicolumn{2}{|l|}{$\mathrm{HDL}^{\mathrm{a}}$, correlation } & 0.084 & $0.241^{c}$ & 0.191 & $0.007^{c}$ \\
\hline \multirow[t]{2}{*}{ Health status } & Poor & $\begin{array}{l}31.85 \\
(10.32)\end{array}$ & $<0.001^{b}$ & $\begin{array}{l}23.91 \\
(17.09)\end{array}$ & $0.002^{b}$ \\
\hline & Good & $\begin{array}{l}23.66 \\
(10.36)\end{array}$ & & $\begin{array}{l}18.19 \\
(14.58)\end{array}$ & \\
\hline \multicolumn{6}{|c|}{ Behavioural and psychosocial characteristics } \\
\hline \multirow[t]{2}{*}{ Medication adherence } & Adherent & $\begin{array}{l}19.74 \\
(7.26)\end{array}$ & $<0.001^{b}$ & $\begin{array}{l}19.75 \\
(15.47)\end{array}$ & $0.271^{b}$ \\
\hline & Non-adherent & $\begin{array}{l}29.71 \\
(11.00)\end{array}$ & & $\begin{array}{l}21.78 \\
(16.13)\end{array}$ & \\
\hline \multirow[t]{3}{*}{ Medication underuse } & No underuse & $\begin{array}{l}26.14 \\
(12.98)^{\mathrm{e}}\end{array}$ & $0.017^{d}$ & $\begin{array}{l}18.74 \\
(14.78)^{\mathrm{e}}\end{array}$ & $<0.001^{d}$ \\
\hline & Cost-related & $\begin{array}{l}30.33 \\
(7.40)^{\mathrm{e}}\end{array}$ & & $\begin{array}{l}32.75 \\
(27.59)^{\mathrm{e}}\end{array}$ & \\
\hline & Non-cost-related & $\begin{array}{l}28.30 \\
(8.51)\end{array}$ & & $\begin{array}{l}21.78 \\
(11.65)^{f}\end{array}$ & \\
\hline
\end{tabular}




\begin{tabular}{|c|c|c|c|c|c|}
\hline & $\begin{array}{l}\text { Both cost- and } \\
\text { non-cost }\end{array}$ & $\begin{array}{l}31.64 \\
(19.66)\end{array}$ & & $\begin{array}{l}42.80 \\
(19.92)^{e, f}\end{array}$ & \\
\hline Dietary behaviours, correlation & & -0.347 & $<0.001^{c}$ & -0.283 & $<0.001^{c}$ \\
\hline Exercise, correlation & & -0.271 & $<0.001^{c}$ & -0.004 & $0.944^{c}$ \\
\hline Blood glucose testing, correlation & & -0.245 & $<0.001^{c}$ & -0.089 & $0.125^{c}$ \\
\hline Foot care, correlation & & -0.217 & $<0.001^{c}$ & -0.077 & $0.187^{c}$ \\
\hline \multirow[t]{2}{*}{ Smoking } & Yes & $\begin{array}{l}27.89 \\
(8.37)\end{array}$ & $0.470^{b}$ & $\begin{array}{l}22.40 \\
(18.70)\end{array}$ & $0.399^{b}$ \\
\hline & No & $\begin{array}{l}28.83 \\
(12.04)\end{array}$ & & $\begin{array}{l}20.13 \\
(15.39)\end{array}$ & \\
\hline \multicolumn{6}{|l|}{ Self-efficacy } \\
\hline \multirow[t]{2}{*}{$\begin{array}{l}\text { - In taking diabetes } \\
\text { medications as prescribed }\end{array}$} & Not confident & $\begin{array}{l}34.25 \\
(12.59)\end{array}$ & $<0.001^{b}$ & $\begin{array}{l}30.13 \\
(15.69)\end{array}$ & $0.015^{b}$ \\
\hline & Confident & $\begin{array}{l}27.04 \\
(10.39)\end{array}$ & & $\begin{array}{l}20.28 \\
(15.71)\end{array}$ & \\
\hline \multirow[t]{2}{*}{$\begin{array}{l}\text { - In ability to carry out self- } \\
\text { care activities }\end{array}$} & Not confident & $\begin{array}{l}33.32 \\
(12.71)\end{array}$ & $<0.001^{b}$ & $\begin{array}{l}26.61 \\
(14.14)\end{array}$ & $0.001^{b}$ \\
\hline & Confident & $\begin{array}{l}25.46 \\
(8.88)\end{array}$ & & $\begin{array}{l}19.09 \\
(15.95)\end{array}$ & \\
\hline
\end{tabular}

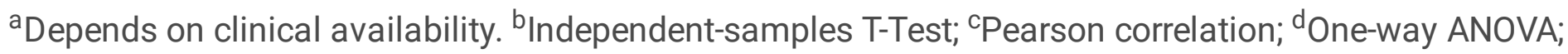
e,fCategories with statistically significant differences, according to Tukey HSD Post Hoc Test.

Table 3. Multivariate regression models for the predictors of diabetes distress stratified by ethnicity 


\begin{tabular}{|c|c|c|c|c|}
\hline \multirow[t]{2}{*}{ Variable } & \multicolumn{2}{|c|}{ Arabic-speaking patients } & \multicolumn{2}{|c|}{ English-speaking patients } \\
\hline & Coefficient & p-value & Coefficient & p-value \\
\hline Constant & 55.33 & $<0.001$ & 69.6 & $<0.001$ \\
\hline Age & -0.348 & $<0.001$ & -0.362 & $<0.001$ \\
\hline \multicolumn{5}{|l|}{ Level of education } \\
\hline High school & -2.93 & 0.026 & & \\
\hline Any tertiary education & -2.67 & 0.095 & & \\
\hline \multicolumn{5}{|l|}{ Functional health literacy } \\
\hline Adequate & 2.05 & 0.163 & & \\
\hline \multicolumn{5}{|l|}{ Employment status } \\
\hline Not employed & 3.33 & 0.009 & & \\
\hline Diabetes duration & -0.177 & 0.126 & & \\
\hline \multicolumn{5}{|l|}{ Diabetes co-morbidities } \\
\hline Yes & 2.75 & 0.060 & & \\
\hline \multicolumn{5}{|l|}{ HbA1c } \\
\hline$>7 \%(>53 \mathrm{mmol} / \mathrm{mol})$ & 4.39 & 0.006 & & \\
\hline HDL & & & 0.32 & 0.896 \\
\hline \multicolumn{5}{|l|}{ Health status } \\
\hline Good & -2.88 & 0.028 & -3.78 & 0.074 \\
\hline \multicolumn{5}{|l|}{ Medication adherence } \\
\hline Non-adherent & -0.65 & 0.732 & & \\
\hline \multicolumn{5}{|l|}{ Medication underuse } \\
\hline Cost-related underuse & 8.11 & $<0.001$ & -2.57 & 0.666 \\
\hline Non-cost related underuse & -0.82 & 0.606 & -2.04 & 0.486 \\
\hline Both cost- and non-cost-related underuse & 3.38 & 0.094 & 18.46 & 0.002 \\
\hline Dietary behaviours & -1.394 & 0.068 & -2.733 & 0.004 \\
\hline Exercise & -1.711 & 0.006 & & \\
\hline Blood glucose testing & 0.150 & 0.725 & & \\
\hline Foot care & 0.306 & 0.442 & & \\
\hline
\end{tabular}


Self-efficacy - medication taking

Confident

$-0.99$

0.617

$-10.10$

0.057

Self-efficacy - carrying out self-care

Confident

$-3.97$

0.009

$-5.35$

0.064

Model summary

F-value: 11.41

p-value: $<0.001$

$R^{2}: 52.28 \%$

$R^{2}(\operatorname{adj}): 47.62 \%$
Model summary

F-value: 8.99

p-value: $<0.001$

$R^{2}: 35.49 \%$

$R^{2}$ (adj): $31.54 \%$

Figures in bold are statistically significant at $5 \%$ significance level.

Reference categories: '<High school' for level of education, 'Inadequate health literacy' for functional health literacy, 'Employed' for Employment status, 'No' for co-morbidities, ' $\leq 7 \%$ ( $\leq 53 \mathrm{mmol} / \mathrm{mol})$ ' for $\mathrm{HbA} 1 \mathrm{c}$ level, 'Poor' for health status, 'Adherent' for medication adherence, 'No underuse' for medication underuse, 'Not confident' for each self-efficacy item.

\section{Figures}

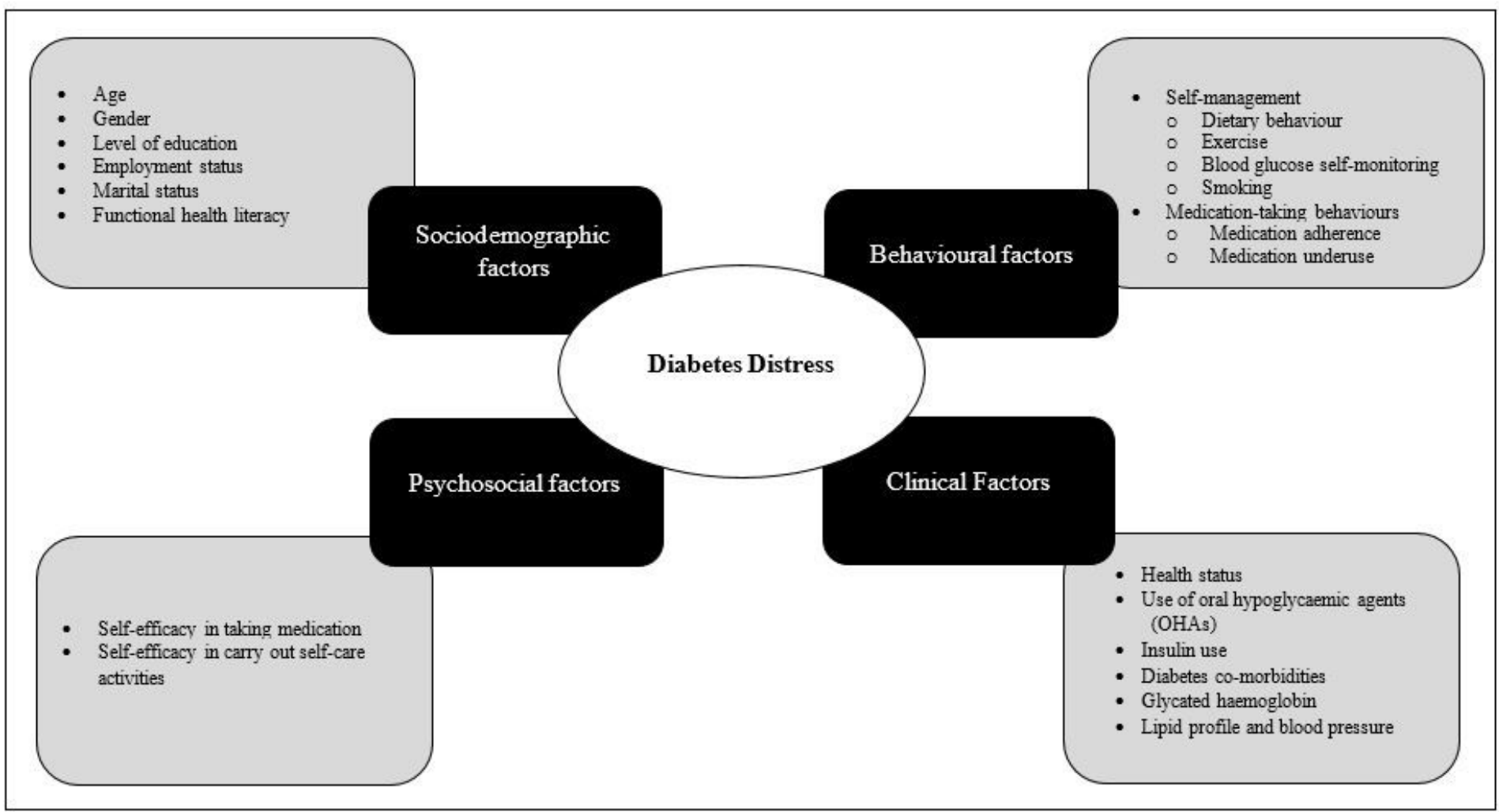


Conceptual Framework

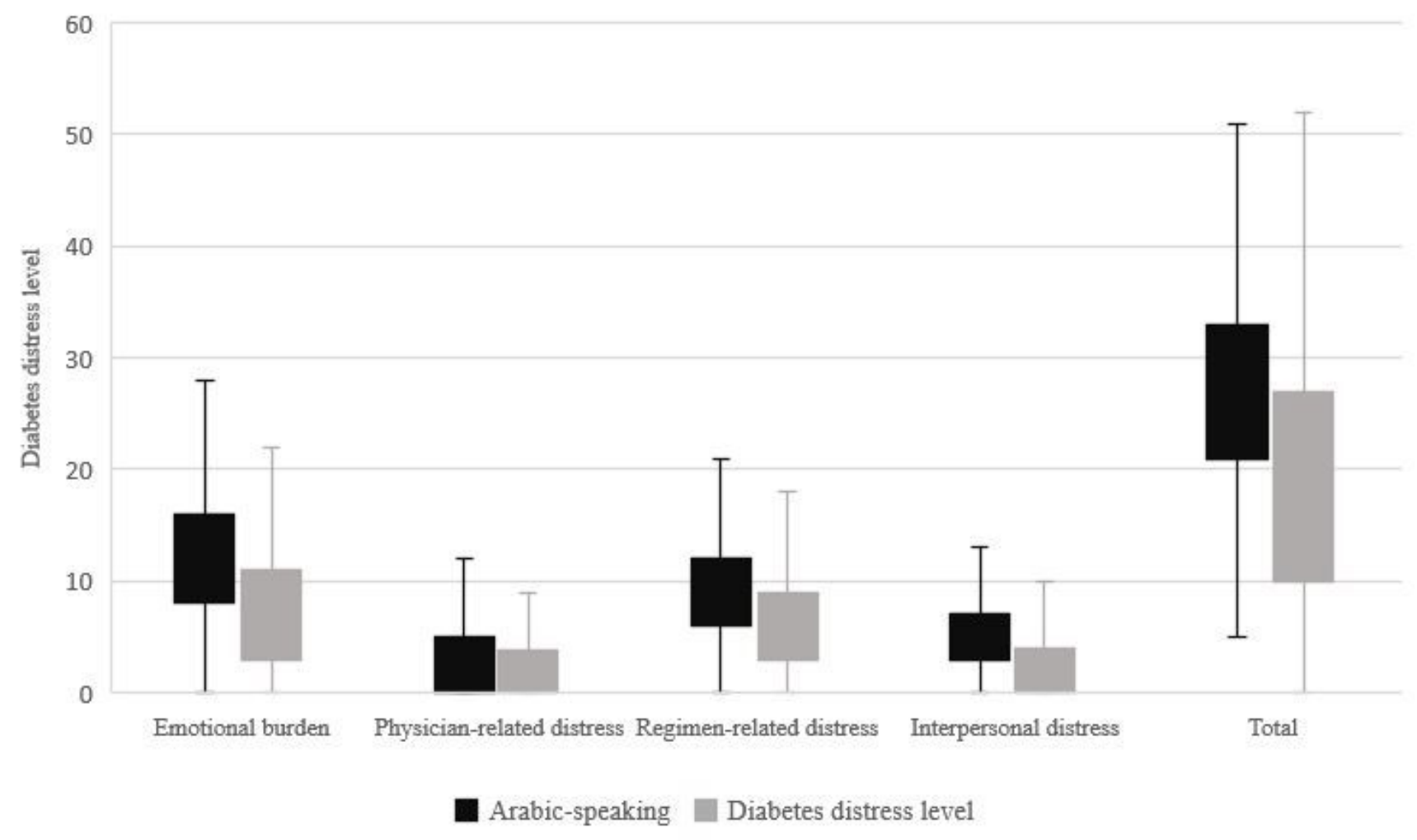

Figure 2

Diabetes distress level among Arabic-speaking and English-speaking patients with type 2 diabetes times 